\title{
DIGITAL TWINNING OF THE BUILT ENVIRONMENT - AN INTERDISCIPLINARY TOPIC FOR INNOVATION IN DIDACTICS
}

\author{
W. Wahbeh ${ }^{1, *}$, D. Kunz ${ }^{1}$, J.Hofmann ${ }^{1}$, P.Bereuter ${ }^{1}$ \\ ${ }^{1}$ FHNW, School of Architecture, Civil Engineering and Geomatics, 4132 Muttenz, Switzerland - \\ (wissam.wahbeh, dominique.kunz, joachim.hofmann, pia.bereuter)@fhnw.ch \\ Commission IV, WG IV/9
}

KEY WORDS: Digital Twin, Virtual Design and Construction, BIM, Construction, Built Environment, IoT

\begin{abstract}
:
The concept of a Digital Twin (DT) takes an increasingly important role in the construction industry and related research fields. It is a concept associated with Industry 4.0; however, the scientific literature does not provide a unique and clear definition of this concept. This paper aims to analyse the definitions of the digital twin to clarify this concept in the related fields of architecture, engineering and construction (AEC). Moreover, this work proposes and employs the concept of a Digital Twin as an objective for a project-based learning approach in a didactical setting. As an interdisciplinary approach, this work demonstrates the potential impact on the traditional didactical frameworks in the educational domain of construction and its value as an opportunity to introduce interdisciplinary expertise to all students in these fields. This work presents a use case applying the concept at the School of Architecture, Civil Engineering and Geomatics of FHNW.
\end{abstract}

\section{INTRODUCTION}

Virtual design and construction (VDC) is a growing reality, and in the near future, it will be the method to plan, execute and maintain a structure. The use of sensors, such as motion, humidity, pressure, smoke and temperature sensors, and the Internet of Things (IoT) in public buildings is widespread. However, the vast amount of data collected through sensors used for facility management (FM) and the digital model used for construction and management of building spaces, are often used separately. The new concept of the DT aims to combine the building model with the information about its objects and the data collected from sensors and actuators together as one system, promising a great potential in streamlining the related workflow in all associated fields of construction.

Researchers at the University of Applied Sciences and Arts Northwestern Switzerland FHNW approach this concept from different points of view. As an academic research centre, involved in collaboration with industry partners in virtual design and construction, it contributes to defining the concept, developing practical solutions to optimising processes and introduces it into academic curricula. Therefore, we will try to shape the definition of DT in the AEC field after having inherited it from other industries. Moreover, we are introducing digital twining in our undergraduate courses, being aware that this topic could take an important role to improve interdisciplinarity in different faculties.

\section{DIGITAL TWIN CONCEPT}

\subsection{Origins of the Concept}

Digitalisation inspired experts in many disciplines, such as engineering, physics and astronomy, to represent digitally an idea (project), to reproduce digitally an existing object, to simulate specific real conditions and for many other purposes. In most of the cases, digitalisation deals with the representation of the reality in some way. Therefore, many concepts evolved connecting the real world and the virtual world. We can identify the following ones: Cyber-Physical Systems (CPS) and the Conceptual Ideal for Product Lifecycle Management (PLM).

To analyse the topic, we first need to deconstruct it into its basic elements, which include the history and origins of the topic, its main concepts, the key relationships through which the concepts interact, research methods, and its applications.

The concept of the DT dates back to a University of Michigan presentation to the industry in 2002 for the formation of a PLM centre by Grieves (2016). PLM is the business activity of managing, in the most effective way, a company's products across their lifecycles (Stark, 2015). At the time, Grieves called the concept, "Conceptual Ideal for PLM". Conceptual Ideal for PLM defines the idea that a digital informational construct about a physical system could be created as an entity on its own. This digital information would be a "twin" of the information that is embedded within the physical system itself and linked with that physical system through the entire lifecycle of the system (Grieves, 2016).

In 2006, Helen Gill from the American National Science Foundation used the term "Cyber-Physical Systems" (CPS) for the first time (Jasperneite, 2012). And the "digital twin" term was first defined in relation to Industry 4.0 at the Hannover Fair in Germany in 2011 (Negri et al 2017).

\subsection{The Definition}

Is "digital twin" an accurate term for gathering existing technologies or does it refer to a new approach to using these technologies? The AEC industry seems to be attracted by the term, "digital twin," however, is still struggling to find a unique definition. Grieves (2016), in his conceptual ideal for PLM, claims that virtual and real systems will be connected as the system goes through the four phases of creation, production

\footnotetext{
* Corresponding author
} 
(manufacture), operation (sustainment / support), and disposal. Moreover, he defines it in the following way: The digital twin is a set of virtual information constructs that fully describes a potential or actual physical manufactured product from the micro atomic level to the macro geometrical level. At its optimum, any information that could be obtained from inspecting a physical manufactured product can be obtained from its Digital Twin (Grieves, 2016).

Within the NASA's technology roadmap, a DT of the flight system is, with comprehensive diagnostic and prognostic capabilities, able to ensure continuous safe operation throughout the service life of system (Piascik, 2012). Kritzinger et. al (2018) differentiate the level of integration between the building and its replica (Figure 1):

- Digital Model: when no automatic data flows between them

- Digital Shadow: when an automatic data flow is possible only in one direction

- Digital Twin: when an automatic data flow is possible in two directions

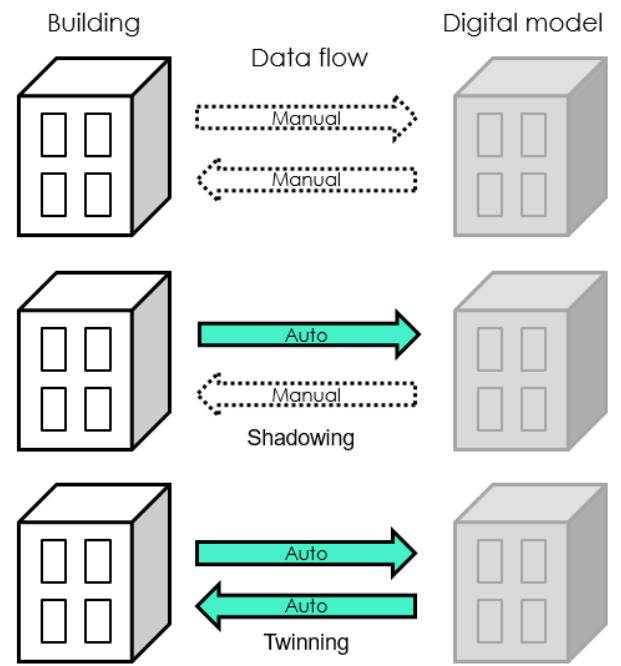

Figure 1. Existence and direction of automatic data flow between the building and its digital representation defines if it is a simple digital model, a shadow of the building, or a digital twin

Wagg et al. (2020) highlight the need for contextualisation of the twinning framework and add that a digital twin can be considered as a process, a product or some combination of both.

Consequently, the authors outline digital twin as a digital replica of the structure and behaviour of a building with interactive connections to it. These connections transmit information (status, usage or analysis data, control commands, etc.). Moreover, a DT can take different forms depending on the level of detail, the degree of automation and the type of connections and information. Thus, a DT maps states (structural and operational) of a real building over time. It can represent an existing building or one that is currently being realized.

\section{DIGITAL TWINNING AS DIDACTICAL GOAL}

The built environment is being digitised and the barriers between disciplines are disappearing, creating a challenge for academic institutions to prepare the students as future experts within the rapidly evolving interdisciplinary field. This requires an intuitive, practical, application-oriented learning environment and interdisciplinary research conditions.

The main ambition of an academic institution is to teach what should be the skills of future experts, namely, teaching for the future. The School of Architecture, Civil Engineering and Geomatics at the FHNW established the Institute of Virtual Design and Construction in 2018 with the intention to integrate building information modelling with its key competences such as interoperability and the related technologies into the academic curricula. The school has started to introduce the new methods and technologies in the different institutes at different levels adapting the contents to the students' backgrounds and ensuring an overview of the method across the disciplines for each discipline and level.

In a university of applied sciences, involving students in applied research is one of the best methods to teach professional, real life subjects. Requirements in applied research differ from basic research. Applied research emphasizes outcome versus conceptual analysis (Azrin, 1977).

This explains very well that involving the students in applied research will develop a practical sensibility to the subject. In a topic like digital twinning, the involved technologies are very heterogeneous, the use cases of a digital twin are numerous, and the imaginable use cases are not well defined. Moreover, the contextualisation of the problem is an open question. To face the DT topic in didactics as an abstracted concept, on the one hand, limits the complexity and, on the other hand, underestimates the potential of the combination of different technologies and data, which could have great possibilities and result in promising new use cases when combined together.

the innovation in didactics in construction that we propose is the use of DT Topic to create educational work contexts that extend beyond the individual disciplines. in this way the resulting exchange of data, knowledge and ideas between students is an added value. This exchange normally takes place little in undergraduate education.

Based on this concept and starting from the need to combine the research and the teaching of the topic, the school initiated a project "Digital Twin Campus Muttenz" (DTCMU), to teach the topic of creating the DT of its own campus, which includes digitizing it, researching the needed technologies, and analysing the use cases. The Project is organised across disciplines and institutes. The duration of the project is 2 years starting from May 2019 with the aim to integrate the result in VDC-related courses. Moreover, new optional interdisciplinary workshops are organised. Estimated number of students to collaborate in the project for 2 years is 50 students.

The didactical goals of the project are the following:

- Defining a layout and methodology to teach VDC as an interdisciplinary topic in the different institutes and promoting exchanges between their students.

- Getting the students involved in applied research in early stages of study (Bachelor \& Master) through creating a building information model and analysing the feasibility of the technologies for the DT applications.

\subsection{Project-based learning approach}

Exactly as in an actual construction process, to create a digital twin, experts from different disciplines are required; they have one goal, namely, to construct the building. For this co-creation, they require planning, organisation, coordination and the 
responsibility to deliver their products correctly while considering the requirements of others in complex workflows.

The DTCMU Project adapts this concept. Over two years, individual students or student groups will contribute to the project through their different studies.

In fact, every group of students contributes with a piece of the puzzle to complete the picture. The pieces are of different types. It requires geometry modelling, information and properties of the construction elements. Furthermore, information of the sensors and actuators in the building, IoT, and information management are required. The students' work may have completely different degrees of complexity and duration depending on the context. Different courses teach the various topics such as BIM, IoT, programming, and modelling. Moreover, the DTCMU Project is a topic in Master and Bachelor theses in different disciplines. So the project invites students to work as groups or individuals to investigate a problem, produce models or solutions. The important objectives are to learn technologies, interoperability and to collaborate using an interdisciplinary overview.

The learning outcomes are divided into three levels. Depending on their level of knowledge, students are therefore asked, to produce a work that will enable them to achieve one of the following goals:

1. To be able to understand the method or the technology

2. To be able to use the method or the technology

3. To be able to assess the method or the technology for specific assignment.

This way it is possible to reach the goal within the existing educational framework. Additionally, we have proposed interdisciplinary workshops mixing students from different disciplines to contribute to the creation of the DT (Figure 2). By this means, we have created interesting interaction between disciplines, which is normally the case in professional environment only outside of academia.

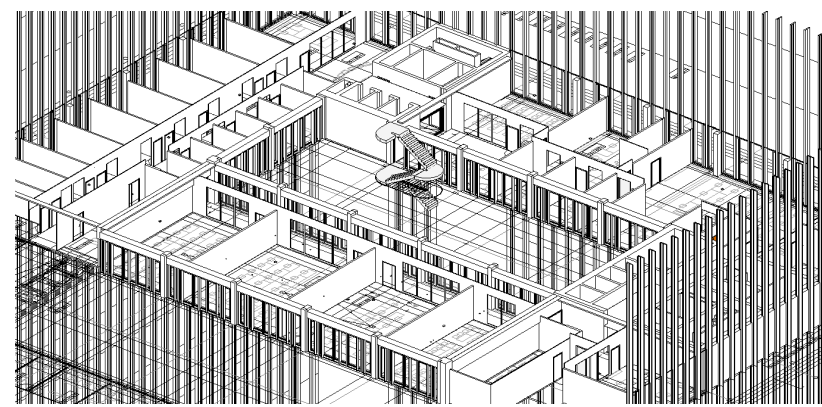

Figure 2. Snapshot of part of the model during BIM modelling workshop in the context of DT

\subsection{Project-related work packages}

Digital twinning is possible only when we combine different technologies. In addition, for existing buildings, it is even more complex, since we need to digitise the physical construction and have to establish a strategy to analyse existing data and systems in the building. Here are the main work packages related to the essential technologies to create digital twin.

- Scanning and reality capturing

- Modelling

- Internet of Things

- Data management and visualisation
These work packages are used to organise research and teaching activities within digital twining activities.

\subsubsection{Scanning and reality capturing}

Three-dimensional laser scanning is now a well-established and widespread technology. It is so precise that it can be used to verify a minimum deviation between an existing building and its planned project (as-built verification).

The advancement of the hardware for data acquisition and software instrumentation of the management of the huge amount of data is in continuous evolution. In addition, the combination between different systems can produce very handy devices that make the survey much faster (Figure 3).

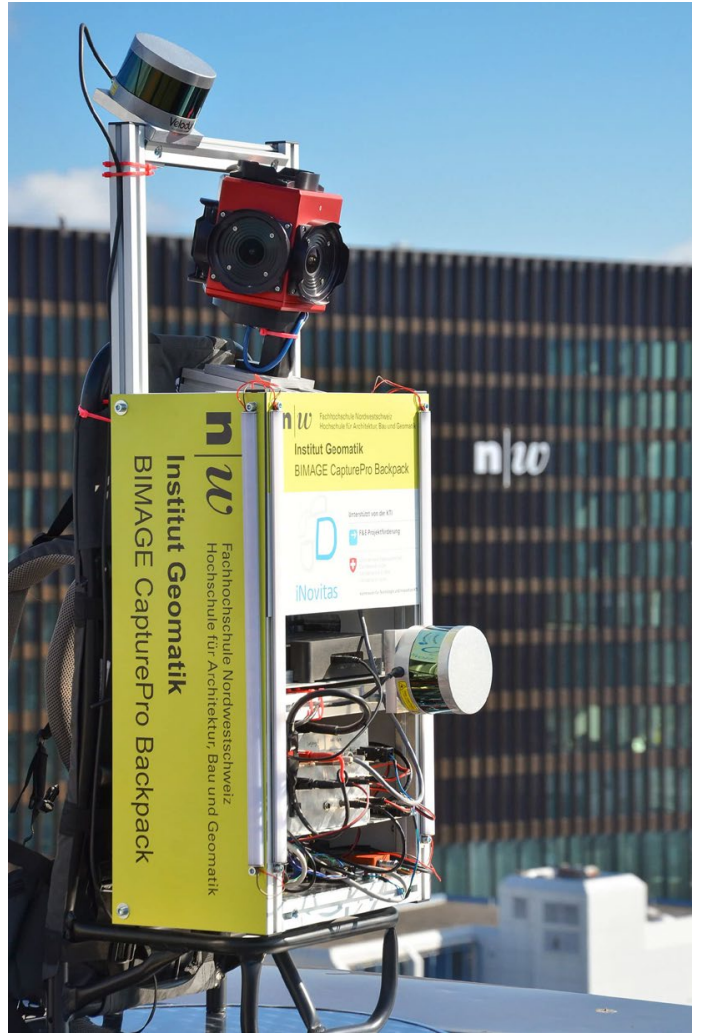

Figure 3. Mobile mapping system (Backpack) developed by FHNW, Institute of Geomatics (Blaser et al 2018)

New image-based mobile reality capturing techniques in combination with cloud technologies, such as presented by Nebiker et al. (2015), hold the potential to provide such data and services in a rapid, cost-efficient and user-friendly manner. Mobile mapping systems are reaching high accuracy levels through combining different data capturing and processing systems such as multi-head panorama cameras for photogrammetric reconstruction, multi-profile LiDAR scanners in addition to IMU and SLAM systems such as the one developed by Blaser et al. (2018) and Cavegn et al. (2018).

Students' works within digital twinning activities related to scanning and reality capturing is to investigate different methods using not only commercial solutions. They are involved in evaluating research products too. This is described in Blaser et al. (2019)

For the DTCMU project, geomatics students are scanning the building. Different parts of the point clouds produced by different courses are combined and geo-referenced locally with a reference to the global system (figure 4). They are prepared 
for use as reference models to other groups for different work packages.

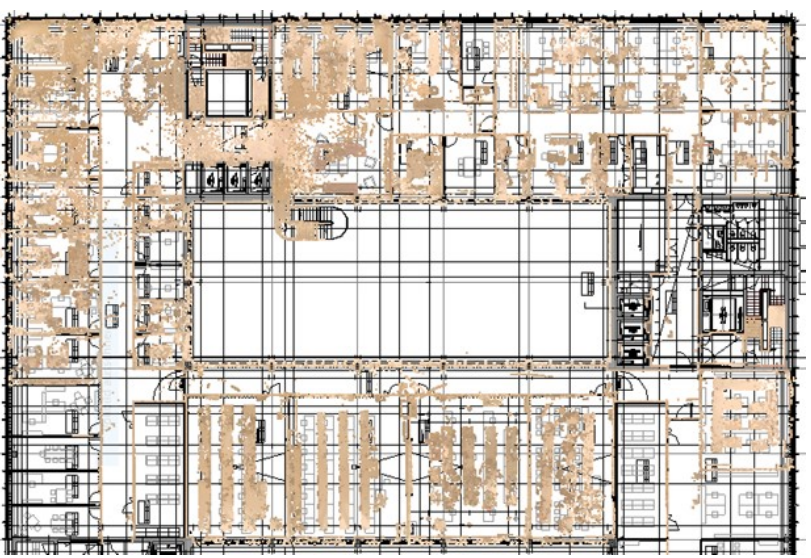

Figure 4. Overlapping horizontal section of the point cloud and the available floor plan

\subsubsection{D Modelling:}

3D modelling is in practice normally a manual process. However, in addition to teaching the manual modelling process, we developed the concept that such a complex topic needs to be supported by innovation even in the process. Moreover, what is significant is to use what the digital tools offer. Next, we introduced some automation aspects into the workflow to simplify the manual procedure and to teach computational methods such as algorithm-based parametric modelling. The new approaches using graphical programming have great potential for modelling aspects as the user can define the rules; the system executes the program according to these rules, and the input parameters (Paris and Wahbeh, 2016). Consequently, this programming process stimulates computational thinking in the students of architecture, civil engineering and geomatics. We believe that an enhanced computational thinking capability is an essential outcome for the students in the AEC field.

Therefore, within the DTCMU project some algorithms were developed by the students to automate modelling steps reducing the manual routines (Figure 5\&6).

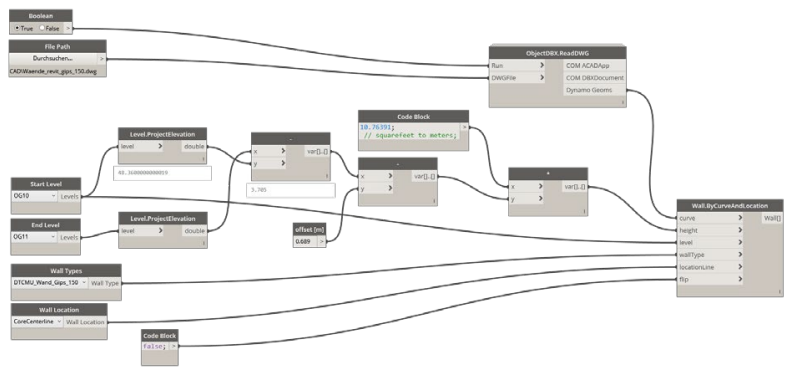

Figure 5. Algorithm developed by student (M. Ammann) to automatically place and adapt objects basing on 2D CAD plans and inputs from the user.

The implemented use cases are, so far, the automatic creation of parametric BIM elements and their adaptation in the model basing on 2D information and user preferences. In addition, the placement of typical object models automatically according to their coordinates retrieved from the point clouds such as technology equipment (sensors, routers) which are fundamental components of the digital twin.

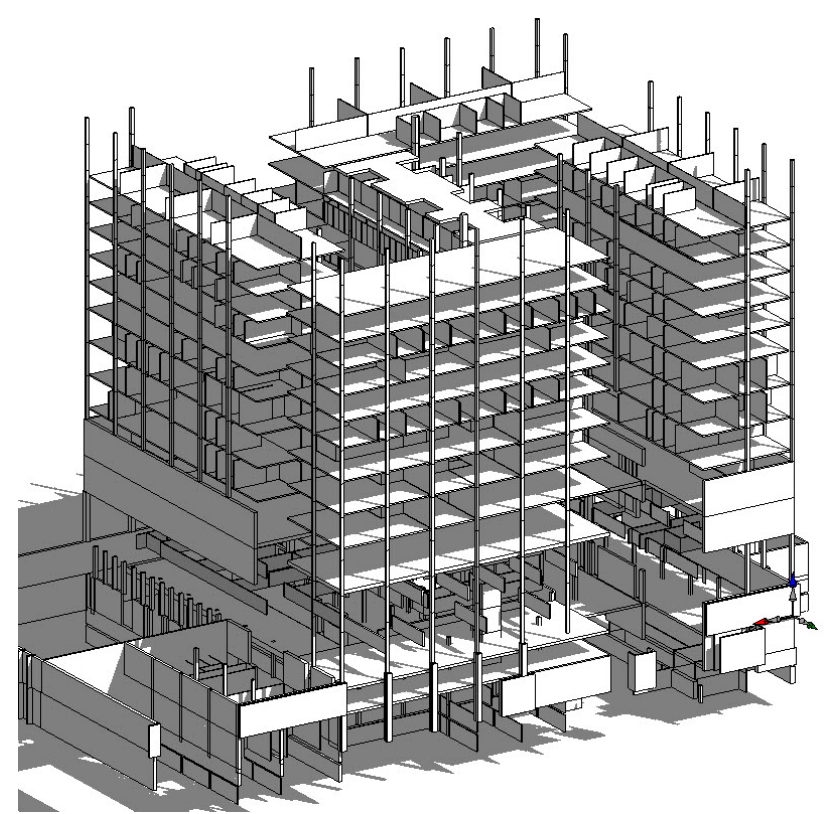

Figure 6. A big part of the campus modelling done using algorithms to automate the process.

\subsubsection{Internet of Things}

The Internet of things (IoT) is the network of objects/things that contain electronics, software, sensors, and actuators, which allows these things to connect, interact, and exchange data (Kankanhalli 2019).

The automatic connection between the digital and the physical worlds are easily and cost-effectively realised thanks to the IoT (Figure 7).

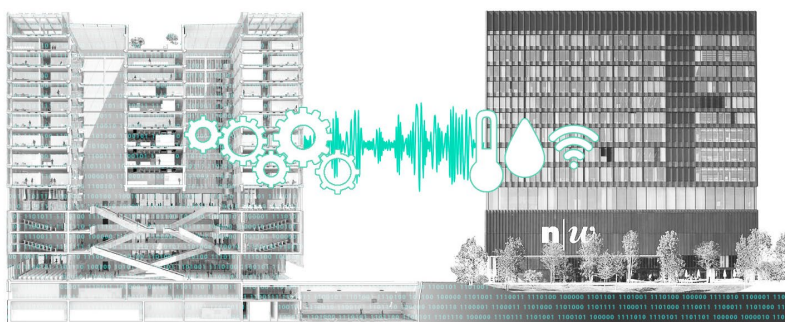

Figure 7. Connection through IoT is needed to connect the building with its digital representation or replica

IoT is already used in modern buildings for technical building automation systems. These systems are sometimes managed and combined together to execute automatic actions to improve comfort and to optimise the use of energy. However, DT is a new mechanism to manage IoT devices and IoT systems-ofsystems throughout their lifecycle (Canedo 2016).

Consequently, the concept DT can be introduced as a new mechanism to use IoT, and when combined with other technologies, it opens the field to new use cases. The possible future use cases are not easily imaginable. The users, sensors, and networks generate a vast amount of data from which applications could be developed and knowledge gained using artificial intelligence techniques. (Kankanhalli 2019).

These innovations change how architectural spaces will be designed in the future. This is a change that will influence future design as did, for example, the invention of the elevator, which allowed buildings to grow in height, and then to change the world's skylines. 
In teaching activities, IoT topic is introduced and within the DTCMU project, the students are involved in the experimentation of use cases of IoT systems for digital twins.

\subsubsection{Information Management and Visualisation}

Data collection with the modern technologies is very fast and reliable; a challenge is how to manage the data. The ability to transform the data into useful information timely is a challenge. BIM asset management and IoT data, which include data architecture, integration and distribution through databases, are fundamental for digital twins. Lu et al (2019) summarise the targets and benefits of current BIM-enabled asset management as follows:

- Accurate and efficient support for decision-making, monitoring and communication;

- Easy retrieval and storage of maintenance, inventory, warranty, installation and operation data;

- Enhancement of collaboration and increase in visualisation;

- Effective management and planning of orders, activities, schedules, labour and space;

- Convenient maintenance and tracking of assets;

- $\quad$ Optimised use of fuel, utilities and materials;

- Facilitation of emergency evacuation planning.

These use cases of DT need stable, standardised, user-friendly and machine-readable databases to be operational.

The collected data by the means of IoT is substantial, for instance, our campus holds about 42000 data collection points (sensors and actuators); if we needed to save its historical data, by saving only one value every hour, more than one million values would need to be stored every day. To analyse the recorded data of the last few years to estimate and optimise for instance the energy use of the future, a considerable amount of data requires storing and appropriate tools of managing and analysis.

Big data is a challenge we face in almost every industry. How we manage and model data is of relevance the different automation systems in the building. The strategy and future development for asset and data management is another important component in the DTCMU project.

\subsection{Experimentations}

The DTCMU project, experiments with some technologies and prepares evaluate some partial processes, concepts and use cases. All the examples use the campus data. Moreover, those experiments are planned to be demonstrations, study cases and development platforms for future students.

3.3.1 Visualisation and dataflow between building information modelling, virtual and augmented reality

The combination of BIM and game engines supplies realistic 3D models for better intuitive interaction with the building model thanks to the powerful 3D and physics engines that reside in modern game engines. These possibilities extend the effectiveness of real-time communication within the BIM environment.

Different use cases proposed in our industry are making use of game engines for virtual simulations and interactions with a building model. These include evacuations in emergencies (Mól et al., 2008), simultaneous data exchange between BIM and VR for collaborative decision-making (Du et al., 2017) and the implementation of a smartphone-based indoor mobile mapping application based on an augmented reality (AR) (Hasler et al.
2019). Different types of research aim to close the gap between the building information model and visualisation aspects (Wang et al., 2014).

This use case is integrated into the project and investigated in our didactic project. Workflows are being created to digitise the building, create a building information model and then to view the geometry and the properties of the construction elements within VR environment (Figure 8).

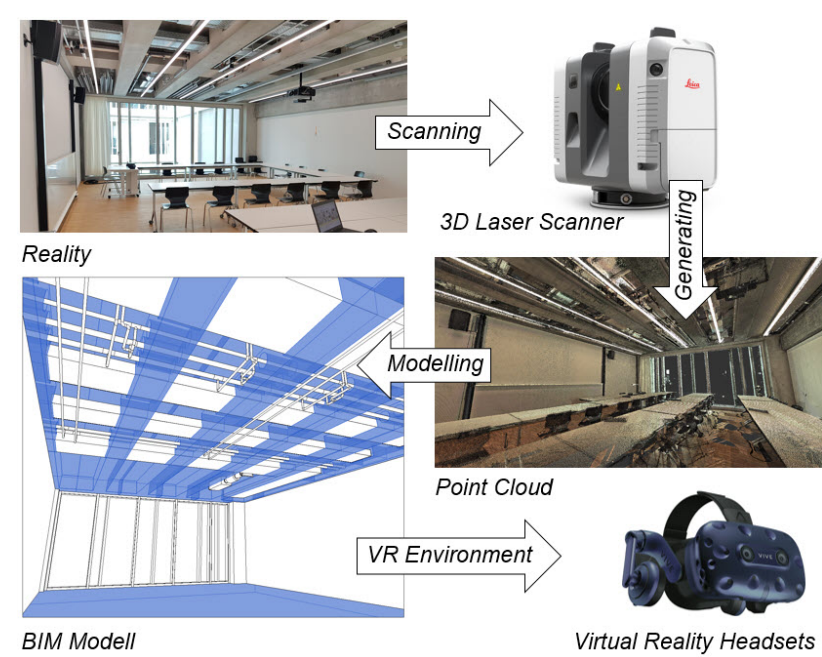

Figure 8. Digitising using laser scanning, BIM modelling and virtual reality

\subsubsection{Mixed Reality for facility management}

During the lifecycle of the building, FM staff gain the greatest benefit from using a DT. However, a DT should interface in a straightforward and simplified way to be truly practical for everyone.

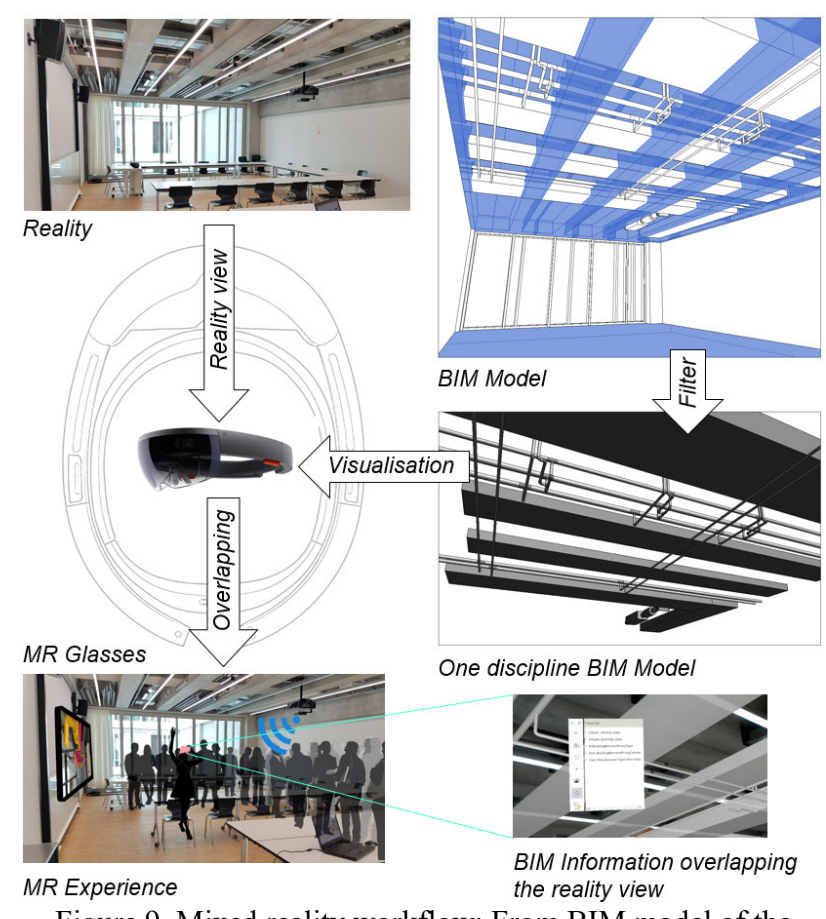

Figure 9. Mixed reality workflow: From BIM model of the campus to an interactive visualisation of object properties for FM use case 
While game engines are not yet as flexible to transmit real-time data for virtual reality and mixed reality using more sophisticated hardware like a hololens can provide more flexibility for this goal. Augmented reality, mentioned earlier, can also guarantee this in part and therefore could be applied for FM tasks (Gheisari et al., 2014). Experimentation on the topic of mixed reality using campus data took place in a VDC course to combine the two realities (Figure 9).

\subsubsection{Internet of Things to connect the sensors and the model}

The campus has a huge number of sensors and actuators, which are not subject to experimentation. Therefore, a physical twin of part of the campus was reproduced from the BIM model, to serve as an experimentation platform. The $3 \mathrm{D}$ printed physical model (1:50 scale) was outfitted with sensors and actuators, and then connected to the BIM model (Figure 10). The prototype includes, so far, a lighting automation system, that, based on the quantity of light received, controls the connected LED lights to guarantee necessary illumination in the space. This mimic the lighting system in our campus building. Additionally, in the experimentation, the system interfaces with the BIM model. The situation is visualised in real time in the BIM model, and it is possible to manage the system directly from it, specifically, to activate/deactivate manual control, to define the lighting threshold, and to define specific lighting parameters such as the colour (RGB).

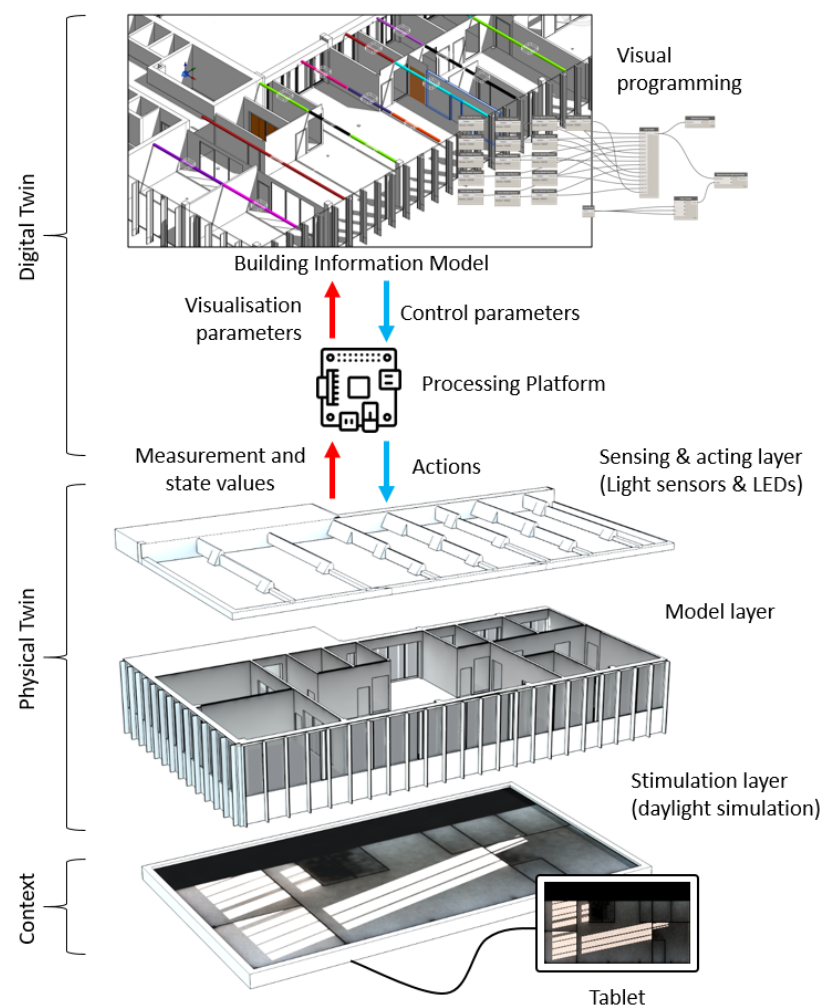

Figure 10. The concept of a prototype created to investigate the interactivity through IoT between a physical model containing sensors and its digital twin

The prototype was planned as a didactical platform for IoT and data management. In addition, it was presented at the Swiss construction fair Swissbau 2020 in Basel (Figure 11).

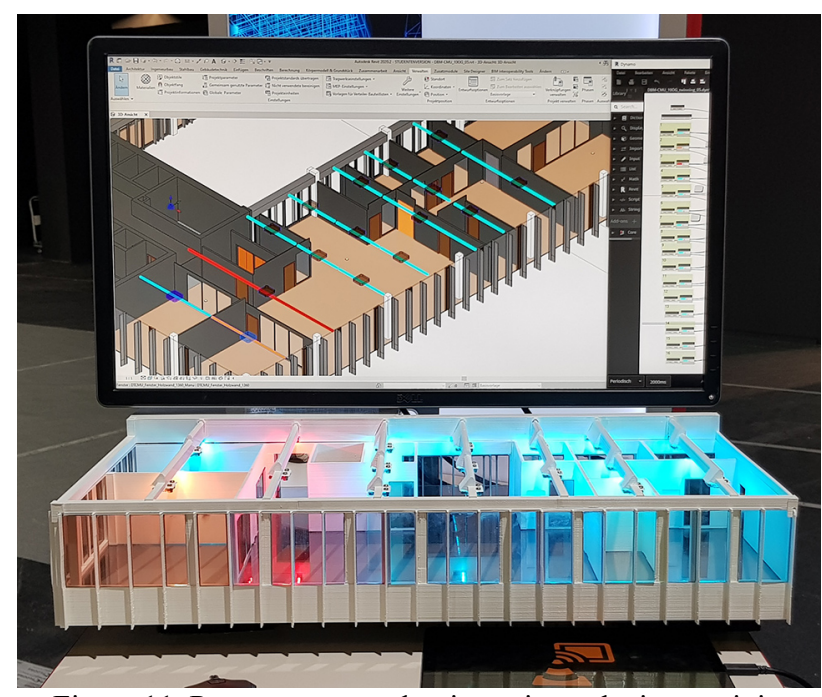

Figure 11. Prototype created to investigate the interactivity through IoT between a physical model containing sensors and its digital twin. Below: 3D printed model of part of the campus, and on the screen, the building information model with the interactive connection between them in two directions

\section{CONCLUSION}

Introducing digital twinning as a topic and including a projectbased learning approach within the existing educational framework is bringing new positive outcomes, which are normally less focused on, such as the coordination, interoperability, and the overview of the whole process and the different available technologies.

The hands-on implementation of the project with the students made it possible to address practical problems, which the students had to solve with interdisciplinary discussions. For the School of Architecture, Civil Engineering and Geomatics, this is a benefit for real future-oriented teaching methods when the boundaries of the disciplines will not be as clear-cut as they currently are, and where technology will play a fundamental role throughout the life cycle of a construction.

\section{ACKNOWLEDGEMENTS}

Thanks to the FHNW Foundation "StiftungFHNW" and the FHNW Teaching Fund "Lehrfonds FHNW" for financing this educational project.

Thanks to the students who contributed to the project. Until the Submission of the paper: (Manuela Ammann, Florian Broch, Fabian Casutt, Julia Kägi, Dominik Schweizer, Géraldine Studemann, Kevin Uebelhart, Johanna Wieland, Nele Ramlow, Ahmed Abdelmoghni, Raphael Börlin, Timo Daniel, Timon Droll, Michel Gerber, Jan Knössel, Raphael Konrad, Daniel Minnig, Pascal Salathé, Hannah Scheibner, Noé Schwaller, Lucien Zenners and Fabio Parisi).

\section{REFERENCES}

Azrin, N.H., 1977. A strategy for applied research: learning based but outcome oriented. American Psychologist, 32(2), p.140.

Blaser, S., Cavegn, S., Nebiker, S., 2018. Development of a Portable High Performance Mobile Mapping System Using The Robot Operating System. ISPRS Annals of Photogrammetry, Remote Sensing \& Spatial Information Sciences, 4(1). 
Blaser, S., Nebiker, S., Wisler, D., 2019. Portable Image-Based High Performance Mobile Mapping System in Underground Environments-System Configuration and Performance Evaluation. ISPRS Annals of Photogrammetry, Remote Sensing \& Spatial Information Sciences, 4.

Canedo, A., 2016, October. Industrial IoT lifecycle via digital twins. Proceedings of the Eleventh IEEE/ACM/IFIP International Conference on Hardware/Software Codesign and System Synthesis (pp. 1-1).

Cavegn, S., Blaser, S., Nebiker, S., Haala, N., 2018. Robust and Accurate Image-Based Georeferencing Exploiting Relative Orientation Constraints. ISPRS Annals of Photogrammetry, Remote Sensing \& Spatial Information Sciences, 4(2).

Du, J., Zou, Z., Shi, Y., Zhao, D., 2017. Simultaneous data exchange between BIM and VR for collaborative decision making. Computing in Civil Engineering (pp. 1-8).

Gheisari, M., Goodman, S., Schmidt, J., Williams, G., Irizarry, J., 2014. Exploring BIM and mobile augmented reality use in facilities management. In Construction Research Congress 2014: Construction in a Global Network (pp. 1941-1950).

Grieves, M., 2016. Origins of the Digital Twin Concept, Florida Institute of Technology. NASA, Working Paper. doi: 10.13140/RG.2.2.26367.61609

Hasler, O., Blaser, S., Nebiker, S., 2019. Implementation and First Evaluation of an Indoor Mapping Application Using Smartphones and AR Frameworks. The International Archives of Photogrammetry, Remote Sensing and Spatial Information Sciences, 42, pp.135-141.

Jasperneite, J., 2012. Was hinter Begriffen wie Industrie 4.0 steckt. Computer \& Automation, 19. https://www.computerautomation.de/steuerungsebene/steuern-regeln/artikel/93559/ (last date of visiting 02.05.2020)

Kankanhalli, A., Charalabidis, Y., Mellouli, S., 2019. IoT and AI for smart government: A research agenda.

Kritzinger, W., Karner, M., Traar, G., Henjes, J., Sihn, W., 2018. Digital Twin in manufacturing: A categorical literature review and classification. IFAC-PapersOnLine 51, 1016-1022. https://doi.org/10.1016/j.ifacol.2018.08.474

Lu, Q., Xie, X., Heaton, J., Parlikad, A.K., Schooling, J., 2019, October. From BIM Towards Digital Twin: Strategy and Future Development for Smart Asset Management. In International Workshop on Service Orientation in Holonic and Multi-Agent Manufacturing (pp. 392-404). Springer, Cham.

Mól, A.C.A., Jorge, C.A.F., Couto, P.M., 2008. Using a game engine for $\mathrm{VR}$ simulations in evacuation planning. IEEE computer graphics and applications, 28(3), pp.6-12.

Nebiker, S., Cavegn, S., Loesch, B., 2015. Cloud-Based Geospatial 3D Image Spaces-A Powerful Urban Model for the Smart City. ISPRS Int. J. Geo-Information, 4(4), pp. 22672291.

Negri, E., Fumagalli, L., Macchi, M., 2017. A Review of the Roles of Digital Twin in CPS-based Production Systems. Procedia Manufacturing 11, 939-948. https://doi.org/10.1016/j.promfg.2017.07.198
Paris, L., Wahbeh, W., 2016. Survey and representation of the parametric geometries in HBIM. Disegnarecon, 9(16), pp.12-1.

Stark, J., 2015. Product lifecycle management. Product lifecycle management Volume 1, pp. 1-29). Springer, Cham.

Wagg, D.J., Gardner, P., Barthorpe, R.J., Worden, K., 2020. On Key Technologies for Realising Digital Twins for Structural Dynamics Applications. Model Validation and Uncertainty Quantification, Volume 3 (pp. 267-272). Springer, Cham.

Wang, X., Truijens, M., Hou, L., Wang, Y., Zhou, Y., 2014. Integrating Augmented Reality with Building Information Modeling: Onsite construction process controlling for liquefied natural gas industry. Automation in Construction, 40, pp.96105. 